Apart from simple dressings to ulcerated lesions, no treatment, such as supportive bandages, was used while the antituberculous therapy was given.

\section{Summary}

Twelve cases of nodular or ulcerative eruptions on the lower legs which showed evidence of tuberculosis are described. Reasons for misdiagnosis are discussed. The occurrence of erythema induratum (Bazin) in Britain and the incidence in older patients are emphasized.
REFERENCES

Audry, C. (1898). Ann. Derm. Syph. (Paris), p. 209.

Bazin, A. P. E. (1861). Leçons théoriques et cliniques sur la scrofule, 2nd ed., p. 146. Delahaye, Paris.

Galloway, J. (1899). Brit. F. Derm., 11, 206.

Montgomery, H., O'Leary, P. A., and Barker, N. W. (1944). Coll. Pap. Mayo Clin., 36, 461 .

Sandberg, D. H., and Adams, J. M. (1962). f. Pediat., 61, 880.

Stegmaier, O. (1959). Arch. Derm., 80, 611.

Telford, E. D. (1937). Ibid., 36, 952.

Whitfield, A. (1901). Amer. F. med. Sci., 122, 828.

Wilkinson, D. S. (1954). Brit. F. Derm., 66, 201.

\title{
Complication Following Fracture-dislocation of Hip
}

\author{
D. W. M. HAW,* M.B., CH.B., B.SC., F.R.C.S.
}

Brit. med. F., 1965, 1, 1111-1112

I would like to report an unusual case of hazard to the sciatic nerve.

A youth aged 17 was riding a motor-cycle when he collided with a car and sustained an injury to his right hip.

On admission to hospital his general condition was good, pulse 80 , blood-pressure $140 / 80$. He had adduction medial rotation and shortening of the right thigh, with all movements of the hip limited by pain and spasm, and an abrasion over the right patella. There was no motor or sensory loss in the leg and the circulation was not impaired. Radiographs showed a posterior fracture-dislocation of the right hip with a large posterior fragment of acetabulum (see Fig. 1).

It was decided to perform an open operation and fix the large posterior fragment with a screw. Closed reduction was done first, with flexion of the hip to right angles, traction, and internal rotation. This was accomplished easily at the first attempt. A subsequent radiograph showed a satisfactory reduction.

* Senior Orthopaedic Registrar, Hull Royal Infirmary.

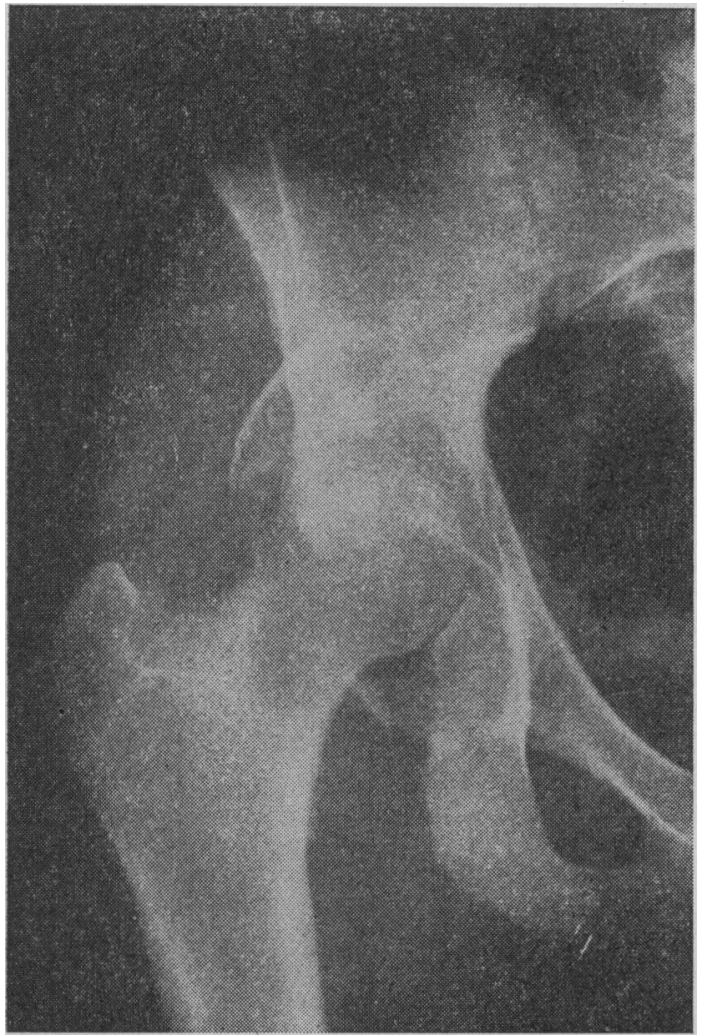

FIG. 1.-Radiograph showing a posterior fracture-dislocation of the hip with a large acetabular fragment.
At operation the hip was approached posteriorly with an inverted L-shaped incision. The fibres of gluteus maximus were split, the incision then being continued vertically into the fascia lata. This procedure exposed the external rotators of the hip. The obturator internus and two gemelli were divided and retracted to give a better exposure. The capsule was torn posteriorly, which revealed the large posterior fragment in good position, but after reduction the sciatic nerve had been trapped between fragments $A$ and $B$ (Fig. 2a). The fracture had passed horizontally through the ischial spine, and at the time of dislocation fragment $A$ had rotated, allowing the sciatic nerve to slip between the fragments. The sciatic nerve was mobilized, and tapes were passed round the nerve, which was coaxed round the spur of fragment $A$. Fragment $A$ was reduced as accurately as possible with a bone hook and fixed to B with a 1-in. $(2.5-\mathrm{cm}$.) vitallium screw (see Fig. $2 \mathrm{~b}$ ), A small slip of pyriformis was sutured under the nerve to protect it from the fracture site. Loss of blood at the operation was less than half a pint. Two pints $(1,140 \mathrm{ml}$.) of blood was replaced.

The patient made an uneventful recovery. On the day after operation there was no evidence of motor or sensory loss in the sciatic nerve. He was immobilized on Hamilton Russell traction for six weeks. Active hip movements were begun one month after the operation. He remained free in bed one week after the traction had been discontinued and was then allowed to walk with crutches. No weight was taken on the affected limb.

He was seen three and a half months after operation. He walked with a slight limp; the Trendelenburg test was negative; flexion of the hip was limited by 15 degrees. A radiograph taken at this time showed that the fracture had united without displacement ; the femoral head showed a normal density and the joint space was somewhat narrowed.

\section{Discussion}

Armstrong (1948), in a review of 101 cases of traumatic dislocation of the hip, recorded seven cases associated with sciatic palsy. In six of these cases a fragment of bone was displaced into the region of the sciatic notch. The only patient who recovered completely was operated on five days after the injury. Two others operated on after a fivemonth interval only partially recovered. The remaining four showed no recovery.

Watson-Jones (1953) emFIG. 2. - Diagram, a posterior view, (a) showing the
sciatic nerve trapped between fragments $A$ and $B$. (b) Fragments $A$ and $B$ fixed with a vitallium screw. 
immediate reduction of the displaced acetabular fragments in cases of sciatic-nerve palsy. He stated that the nerve was usually stretched over the sharp margin of the tilted fragment and that recovery was jeopardized by delay.

The decision to operate in this case was taken because the large posterior fragment could be fixed more securely with internal fixation than by conservative treatment. If an operation had not been performed the patient might have developed a delayed sciatic palsy due to movements of the fragment or to involvement in the healing fracture. This emphasizes the need for open reduction in fracture-dislocations of the hip with large posterior fragments of the acetabulum even without clinical evidence of sciatic palsy.

My thanks are due to Mr. R. C. Tatham for permission to publish this case.

\section{REFERENCES}

Armstrong, J. R. (1948). F. Bone ft Surg., 30B, 430. Watson-Jones, R. (1953). Ibid., 35B, 147.

\section{Medical Memoranda}

\section{Involvement of Anterior Horn of Spinal Cord in Infectious Mononucleosis}

Brit. med.7., 1965, 1, 1112

Neurological complications of infectious mononucleosis are rare. In 1946 Wechsler et al. reported 556 cases of infectious mononucleosis, in which the incidence of involvement of the nervous system was less than $1 \%$. Hoagland (1960), reporting his experience of 200 cases, mentioned only two with neurological complications. Though in the past paralysis of muscles due to involvement of peripheral spinal nerves has been reported by Richardson (1942), Saksena (1943), and Erwin et al. (1959), paralysis due to a lesion of the anterior horn of the spinal cord has not hitherto been reported. The following case report describes this unusual complication of infectious mononucleosis.

\section{CASE REPORT}

In September 1964 a 20-year-old skilled labourer developed a sore throat which lasted for three days. He felt increasingly weak and tired for a week after this, but remained ambulant. At the end of this period he was found to have a temperature of $102^{\circ} \mathrm{F}$. $\left(38.9^{\circ}\right.$ C.) for which he was sent to bed. Within a day or two he developed pain in the middle of his back and in the upper part of his left arm in the deltoid region. He also noticed that the muscles around his left shoulder twitched from time to time. Three or four days after the onset of pain he found that he could not raise his left upper arm above the shoulder. He had been vaccinated against poliomyelitis five years previously, having had the usual three injections of Salk vaccine.

When he was admitted to hospital, two weeks after the onset of illness, his temperature was $100^{\circ} \mathrm{F}$. $\left(37.8^{\circ} \mathrm{C}\right.$.). There was a faint maculopapular erythematous eruption over the trunk, forearms, and thighs and a moderate degree of enlargement of lymph nodes in the posterior cervical, axillary, and inguinal regions, the cervical lymph nodes being both visible and palpable. The spleen was firm and palpable $3.5 \mathrm{~cm}$. below the costal margin and the liver was soft and palpable $3 \mathrm{~cm}$. below the costal margin. Muscular power was markedly diminished in the left shoulder, abductors (deltoid and supraspinatus) and external rotators (posterior fibres of deltoid, teres minor, and infraspinatus) being affected. Diminution of the left triceps jerk was found. No sensory changes could be detected on repeated examination on different occasions. Muscular fasciculation was never seen.

A blood count showed a haemoglobin of $14.2 \mathrm{~g} . \%$; white blood cells $18,000 /$ c.mm. (neutrophils $9 \%$, lymphocytes $7 \%$, glandularfever type cells, $84 \%$ ). The Paul-Bunnell heterophile antibody test was positive in a $1 / 1,280$ titre of unabsorbed serum, positive in a 1/1,280 titre of serum absorbed with guinea-pig kidney emulsion, and positive in less than $1 / 10$ titre of serum after absorption with ox-blood cells. Liver function tests showed $530 \mu \mathrm{mol} . / \mathrm{hr} . / 100 \mathrm{ml}$. of serum glutamic pyruvic transaminase (normal range 22-92), $270 \mu \mathrm{mol} . / \mathrm{hr} . / 100 \mathrm{ml}$. of serum glutamic oxalacetic transaminase (normal range $35-107$ ), and $848 \mu \mathrm{mol} . / 100 \mathrm{ml}$. of serum alkaline phosphatase (normal range 156-576); these results suggested hepatic cellular necrosis. A throat swab did not reveal any pathogenic organisms. A radiograph of the chest was clear. The C.S.F. pressure was $170 \mathrm{~mm}$. and the C.S.F. protein $70 \mathrm{mg} . / 100 \mathrm{ml}$. ; only one lymphocyte was seen per c.mm. Tissue culture failed to demonstrate any virus in the faeces, and virus complement fixation tests were negative in several blood samples.

The absence of sensory changes makes it unlikely that the (prednisolone). All symptoms and signs disappeared within a fortnight, except the motor paralysis of the affected group of shoulder muscles. This partial recovery was probably due to natural healing processes, and it is doubtful if the corticosteroid treatment played any significant part. Despite immobilization and subsequent physiotherapy, at the end of four months the paralysis showed no improvement. The left supraspinatus, infraspinatus, deltoid, and triceps muscles showed atrophy. Power of external rotation and abduction of the shoulder remains nil.

\section{COMment}

The absence of sensory changes makes it unlikely that the lesion was in the peripheral nerves. In fact, the close similarity of the clinical features of the paralysis to those of poliomyelitis makes it highly probable that it was in the anterior horn cells (or in the anterior root). It is theoretically possible that this was in fact poliomyelitis, coincident with infectious mononucleosis, but the previous immunization with Salk vaccine makes this unlikely. It seems more probable that in this case there was genuine damage to anterior horn cells by the hypothetical virus of infectious mononucleosis.

I am grateful to Dr. John Forbes for his encouragement, criticism, and permission to report this case.

\section{S. K. MUKHERJEE, M.B., B.S., M.R.C.P.ED., D.T.M.\&H., Medical Registrar, Wrexham Group of Hospitals.}

\section{REFERENCBS}

Erwin, W., Weber, R. W., and Manning, R. T. (1959). Amer. F. med. Sci., 238, 699 .

Hoagland, R. J. (1960). Amer. F. med. Sci., 240, 21.

Richardson, J. S. (1942). Lancet, 1, 618.

Saksena, H. C. (1943). Brit. med. Ұ., 2, 267.

Wechsler, H. F., Rosenblum, A. H., Sills, C. T. (1946). Ann. intern. Med., 25, 236 . 